\title{
ANALISIS PENGARUH CORPORATE SOCIAL RESPOSIBILITY (CSR) PERUSAHAAN (DIVERSITY, EMPLOYEE SUPPORT DAN ENVIROMENT) TERHADAP KINERJA KARYAWAN (STUDI PADA PT. AQUA GOLDEN MISISIPI CITEUREUP)
}

\author{
Ruli Indrawan \\ Indrawan.ruli@gmail.com \\ Universitas Ahmad Dahlan \\ Utik Bidayati \\ utikbidayati@yahoo.com \\ Universitas Ahmad Dahlan
}

\begin{abstract}
ABSTRAK
The purpose of this study was to determine the effect of Corporate Social Responsibility (CSR) of the Company (Diversity, Employee Support, and Environment) on Employee Performance at PT. Aqua Golden Misisipi Citeureup either partially (individually) or simultaneously (together). The population in this study amounted to 767 employees and then taken as many as 90 samples using purposive sampling technique sampling. The type of data is primary data and data collection using a questionnaire that has been tested for validity using confirmatory factor analysis (CVA), and reliability testing using Alpha Crobach, analysis techniques using Multiple Regression. Based on the analysis with statistical tools SPSS V 20 it can be concluded that the employee support variable (X2) partially influences employee performance (Y) while the diversity variable (X1) and environment (X3) partially does not significantly influence employee performance (Y ). While simultaneously (together) diversity (X1), employee support (X2) and environment (X3) significantly influence employee performance (Y) at PT. Aqua Golden Misisipi Citeureup.
\end{abstract}

Keywords: Corporate Social Responsibility; Diversity; Employee Support; Environment; Employee Performance.

\begin{tabular}{l}
\hline \multicolumn{3}{c}{ PENDAHULUAN } \\
Sumber daya manusia merupakan \\
salah satu sumber daya yang paling \\
menentukan sukses tidaknya suatu \\
organisasi. Dalam era globalisasi, masalah \\
sumber daya manusia menjadi sorotan \\
maupun tumpuan bagi perusahaan untuk \\
tetap dapat bertahan. Sumber daya \\
manusia merupan peran utama dalam \\
setiap kegiatan perusahaan. \\
Keberadaan perusahaan tidak lepas \\
dari lingkungan mereka berada. Aktivitas \\
perusahaan dapat menimbulkan dampak \\
pada lingkungan hidup sehingga \\
perusahaan diharapkan tidak hanya \\
memikirkan perolehan laba usaha, tetapi
\end{tabular}

juga mempertimbangkan faktor lingkungan hidup dalam melaksanakan kegiatannya. Namun perusahaan seringkali mengabaikan prinsip dari memaksimalkan laba itu sendiri, diantaranya pengabaian aspek hubungan kemanusiaan dengan tenaga kerja, sedangkan aspek tersebut sangat berpengaruh terhadap kondisi kelangsungan hidup perusahaan secara langsung atau tidak langsung. Dengan kata lain jika terjadi hal-hal yang mengancam kontinuitas perusahaan, maka jalan keluarnya mengandung biaya yang relatif lebih tinggi.

Karyawan merupakan aset bagi perusahaan sebagai penggerak bagi setiap kegiatan yang ada dalam suatu perusahaan 
dan keberadaannya sangat menentukan dinamisasi serta mobilisasi perusahaan. Oleh karena itu perusahaan harus selalu berusaha meningkatkan kepedulian terhadap kualitas sumber daya manusianya agar dapat menjalankan aktivitas kerjanya dengan maksimal. Bentuk kepedulian perusahaan terhadap karyawan dapat dilakukan dengan menjalankan program tanggung jawab sosial perusahaan.

Dalam hal ini perusahaan sering kali mengabaikan hubungan perusahaan dengan karyawan yang dapat menimbulkan berkurangnya kinerja para karyawan. Kinerja para karyawan sering mengalami penurunan, hal ini dikarenakan perusahaan sering melupakan aspek penting dari membentuk hubungan yang harmonis antara perusahaan dengan karyawan. Aspek terpenting dalam hal ini adalah sebuah tanggung jawab sosial yang dilakukan perusahaan untuk membentuk sebuah hubungan yang harmonis sehingga kinerja para karyawan dapat menjadi lebih optimal.

Perusahaan yang melupakan tanggung jawab sosialnya terhadap karyawan akan merasakan dampak yang negative dari kinerja karyawan. Dampak yang dapat ditimbulkan dapat dibagi menjadi 2 bagian yaitu, dampak lingkungan dan dampak sosial. Semua jenis dampak yang ditimbulkan perusahaan akan memberikan risiko yang mempengaruhi bisnis yang dijalankan oleh aktivitas perusahaan.

\section{Corporate Social Responsibility} (CSR) adalah komitmen perusahaan untuk memberikan kontribusi jangka panjang terhadap satu isu tertentu di masyarakat atau lingkungan untuk dapat menciptakan lingkungan yang lebih baik. Kontribusi dari perusahaan ini bisa berupa banyak hal, misalnya : bantuan dana, bantuan tenaga ahli dari perusahaan, bantuan berupa barang, dll.

Di sini perlu dibedakan antara program Corporate Social Responsibility dengan kegiatan charity (amal). Kegiatan charity (amal) hanya berlangsung sekali atau sementara waktu dan biasanya justru menimbulkan ketergantungan publik terhadap perusahaan.

Menurut Trinidad and Tobacco Bureau of Standard (TTBS) menyimpulkan bahwa tanggung jawab sosial perusahaan atau Corporate Social Responsibility (CSR) terkait dengan nilai dan standard yang dilakukan berkenaan dengan beroperasinya suatu perusahaan, maka Corporate Social Responsibility (CSR) diartikan sebagai komitmen usaha untuk bertindak secara etis, beroperasi secara legal dan berkontribusi untuk peningkatan ekonomi, bersamaan dengan peningkatan kualitas hidup dari karyawan dan keluarganya, komunitas lokal dan masyarakat secara lebih luas (Azheri, 2011).

Pelaksanaan tanggung jawab sosial perusahaan tidak hanya membawa konsekuensi logis terhadap baik tidaknya citra perusahaan di masyarakat. Selain itu pelaksanaan Corporate Social Responsibility (CSR) juga berperan dalam peningkatan kinerja dan sumber daya perusahaan yang semakin baik dari sebelumnya. Implementasi CSR tersebut dapat diwujudkan dalam peran sosial perusahaan terhadap lingkungan internal perusahaannya, dalam hal ini kesejahteraan hidup para karyawannya. (Raynard, 2002).

Ernst and Young, dalam Anatan (2009) mengemukakan bahwa perusahaan memiliki empat tanggung jawab utama yaitu terhadap karyawan, konsumen, masyarakat, dan lingkungan. Keempat hal tersebut bisa menjadi dasar pertimbangan bagi perusahaan untuk menetapkan program inti dalam melaksanakan Corporate Social Responsibility (CSR) secara spesifik.

Corporate Social Responsibility (CSR) pada perusahaan khususnya tanggung jawab internal perusahaan terhadap karyawan. Beberapa hasil penelitian menunjukkan bahwa pelaksanaan Corporate Social Responsibility (CSR) mempengaruhi 
karyawan. Menurut penelitian yang dilakukan oleh Munthe (2012) yang berjudul pengaruh Corporate Social Responsibility (CSR) terhadap kesejahteraan karyawan, hasil penelitian tersebut menyatakan bahwa dengan adanya program Corporate Social Responsibility (CSR) internal yang dilakukan perusahaan, kesejahteraan karyawan meningkat.

Hasil yang sama dalam penelitian yang dilakukan oleh Aguilera (2007) menunjukkan bahwa tanggung jawab sosial perusahaan berdampak pada meningkatnyan kepuasan, komitmen dan kesetiaan karyawan. Selanjutnya penelitian yang dilakukan Ali Abbas Albdour dan Ikhlas ibrahim Altarawnehb yang berjudul "Corporate Social Responsibility and Employee Engangement in Jordan" hasil pengujian hipotesis hubungan antara Corporate Social Responsibility and Employee internal dan komitmen karyawan menunjukkan hubungan yang signifikan.

Menurut Wineberg, Corporate Social Responsibility (CSR) lebih didasarkan pada nilai-nilai (Valued Based) perusahaan. Karena itu Corporate Social Responsibility (CSR) ditujukan pada jajaran stakeholders dalam pengertian luas yang dibaginya menjadi tiga, yaitu sebagai berikut: (Azheri, 2011)

1. Stakeholder Internal seperti karyawan dan pemegang saham.

2. Stakeholder external seperti konsumen, komunitas masyarakat di sekitar perusahaan, dan LSM.

3. Stakeholder lainnya seperti pemasok, kelompok SRI (Social Responsible Investors), dan licensing partner.

Selanjutnya Sen dan Battacharya (2001) mengidentifikasikan ada enam hal pokok yang termasuk dalam dimensi CSR tersebut antara lain :

1. Community support (dukungan masyarakat): Dukungan sponsor dan amal, program - program pendidikan, kesehatan, kesenian dan sebagainya.

2. Diversity (perbedaan): Kebijakan perusahaan untuk tidak membedakan konsumen dan pekerja dalam hal gender, fisik atau ras-ras tertentu.

3. Employee support (dukungan karyawan) : Berupa perlindungan terhadap tenaga kerja, insentif dan penghargaan serta keselamatan kerja.

4. Environment (lingkungan) : Menciptakan lingkungan yang sehat dan aman, mengelola limbah dengan baik, produk-produk yang ramah lingkungan,dll.

5. Non-U.S operation : Perusahaan bertanggung jawab untuk memberikan hak yang sama bagi masyarakat dunia untuk mendapat kesempatan bekerja antara lain membuka pabrik di luar negeri (abroad operations).

6. Product (produk) : Perusahaan berkewajiban untuk membuat produkproduk yang aman bagi kesehatan, tidak menipu, melakukan riset dan pengembangan produk secara kontinyu dan menggunakan kemasan yang bisa di daur ulang (recycled).

Berdasarkan enam dimensi yang dikemukakan oleh Sen dan Battacharya di atas penulis memfokuskan pada dimensi Corporate Social Responsibility (CSR) internal (Tanggung jawab sosial perusahaan terhadap karyawan) yaitu dimensi diversity, Employee support dan Environment untuk melihat pengaruhnya terhadap kinerja karyawan.

Menurut Triwadiantini (2011) Pelaksanaan Corporate Social Responsibility (CSR) juga berperan dalam peningkatan kinerja dan sumber daya perusahaan yang semakin baik dari sebelumnya. Implementasi CSR tersebut dapat diwujudkan dalam peran sosial perusahaan terhadap lingkungan internal perusahaannya.

Perusahaan yang dijadikan sebagai objek pada penelitian ini yaitu PT. Aqua Golden Misisipi Citeureup yang bergerak dalam bidang produksi air minum dalam kemasan. Kegiatan komersial merupakan kegiatan yang operasional yang diarahkan untuk 
memperoleh keuntungan dengan tidak mengesampingkan pelayanan dan tanggung jawab sosial pada karyawan.

PT. Aqua Golden Misisipi Citeureup memiliki nilai dasar kemanusiaan, keterbukaan, kedekatan, dan antusiasme untuk menjalin hubungan perusahaan dengan karyawan dan meningkatkan kinerja karyawan agar lebih baik kedepannya.

Tujuan dari penelitian ini di antaranya:

1. Guna mengetahui pengaruh konsep Diversity (perbedaan) terhadap kinerja karyawan pada PT. Aqua Golden Misisipi Citeureup.

2. Guna mengetahui pengaruh konsep Employee support (dukungan karyawan) terhadap kinerja karyawan pada PT. Aqua Golden Misisipi Citeureup.

3. Guna mengetahui pengaruh konsep Environment (lingkungan) terhadap kinerja karyawan pada PT. Aqua Golden Misisipi Citeureup.

4. Guna mengetahui konsep Diversity (perbedaan), Employee support (dukungan karyawan) dan Environment (lingkungan) secara simultan terhadap kinerja karyawan pada PT. Aqua Golden Misisipi Citeureup.

\section{REVIEW LITERATUR DAN HIPOTESIS}

\section{Landasan Teori}

1. Corporate Social Responsibility (CSR)

Tanggung jawab sosial perusahaan merupakan proses pengkomunikasian dampak sosial dan lingkungan dari kegiatan ekonomi organisasi terhadap kelompok khusus yang berkepentingan dan terhadap masyarakat secara keseluruhan (Sembiring, 2005).

\section{Diversity (Perbedaan)}

Kebijakan perusahaan untuk tidak membedakan konsumen dan pekerja dalam hal gender, fisik atau ras-ras tertentu.

3. Employee Support (Dukungan Karyawan)

Berupa perlindungan terhadap tenaga kerja, insentif dan penghargaan serta keselamatan kerja.

\section{Enviroment (Lingkungan)}

Menciptakan lingkungan yang sehat dan aman, mengelola limbah dengan baik, produk-produk yang ramah lingkungan,dll.

5. Kinerja Karyawan

Kinerja apabila dikaitkan dengan performance sebagai kata benda (noun), maka pengertian performance atau kinerja adalah hasil kerja yang dapat dicapai oleh seseorang atau kelompok orang dalam suatu perusahaan sesuai dengan wewenang dan tanggung jawab masing-masing dalam upaya pencapaian tujuan perusahaan secara ilegal, tidak melanggar hukum dan tidak bertentangan dengan moral dan etika (Rivai, 2004).

\section{Penelitian Terdahulu}

1. Peneliti Heryani dengan judul Analisis Pengaruh Coorporate Social Responsibilty ( Diversity dan Employee support ) terhadap Kinerja Karyawan. Studi yang di lakukan pada PT. Batu Rona Adimulya menunjukan hasil bahwa indikator Diversity tidak berpengaruh terhadap kinerja karayawan, sedangkan Employee Support merupakan indikator yang mempunyai pengaruh signifikan terhadap kinerja karyawan yang berada di PT. Batu Rona Adimulya.

2. Penelitian Munthe Krisna dengan judul pengaruh CSR terhadap kesejahteraan karyawan. Penelitiannya menunjukkan hasil bahwa dengan adanya program CSR yang di selenggarakan perusahaan berdampak pada kesejahteraan 
masyarakat yang semakin meningkat.

\section{Hipotesis}

H1: Konsep Diversity (perbedaan) berpengaruh positif terhadap kinerja karyawan pada PT. Aqua Golden Misisipi Citeureup.

H2: Konsep Employee support (dukungan karyawan) berpengaruh positif terhadap kinerja karyawan pada PT. Aqua Golden Misisipi Citeureup.

H3: Konsep Environment (lingkungan) berpengaruh positif terhadap kinerja karyawan pada PT. Aqua Golden Misisipi Citeureup.

H4: Konsep Diversity (perbedaan), Employee support (dukungan karyawan) dan Environment (lingkungan) berpengaruh positif secara simultan terhadap kinerja karyawan pada PT. Aqua Golden Misisipi Citeureup.

\section{METODE PENELITIAN}

\section{Populasi dan Sampel}

Populasi adalah wilayah generalisasi yang terdiri atas obyek/subyek yang mempunyai kualitas dan karakteristik tertentu yang di tetapkan oleh peneliti untuk dipelajari dan kemudian di tarik kesimpulannya (Sugiyono, 2016). Populasi dalam penelitian ini adalah seluruh karyawan di PT. Aqua Golden Misisipi Citeureup.

Menurut Sugiyono (2016) sampel adalah bagian dari jumlah dan karakteristik yang dimiliki oleh populasi tersebut. Bila populasi besar, dan peneliti tidak mungkin mempelajari semua yang ada pada populasi, misal karena keterbatasan dana, tenaga dan waktu, maka peneliti dapat menggunakan sampel yang diambil dari populasi itu.

Dalam penelitian ini sampel yang diambil adalah seluruh karyawan di PT.
Aqua Golden Misisipi Citeureup yang sedang mengikuti program CSR dari perusahaan dengan jumlah sampel 90 karyawan dari 767 karyawan.

\section{Definisi Operasional}

1. Variabel Independen

a. Diversity (Perbedaan)

Diversity

(perbedaan) merupakan keragaman atau berbagai macam perbedaan kondisi dan latar belakang karyawan (Azwar, 2001).

b. Employee Support (Dukungan Karyawan)

Employee Support (dukungan karyawan) merupakan wujud dari dukungan yang diberikan oleh perusahaan kepada karyawan dengan tujuan untuk memotivasi karyawan sehingga kinerja karyawan meningkat.

c. Enviroment (Lingkungan)

Menurut Alex S. Nitisemito dalam Artha (2013) lingkungan kerja adalah segala sesuatu yang ada disekitar para pekerja dan yang dapat memperngaruhi dirinyadalam menjalankan tugas-tugas yang di bebankan.

\section{Variabel Dependen}

Variabel dependen (Y) yang digunakan dalam penelitian ini Kinerja Karyawan. Kinerja Karyawan adalah hasil kerja seorang karyawan selama periode tertentu yang dinilai dengan serangkaian tolak ukur yang berkaitan langsung dengan tugas seseorang serta kriteria yang ditetapkan.

\section{Uji Instrumen}

1. Uji Validitas

Uji validitas adalah ukuran yang menunjukkan sejauh mana instrumen pengukuran mampu mengukur apa yang ingin diukur (Sugiyono, 2016). Uji validitas dalam penelitian ini menggunakan metode confirmatory 
factor analysis (CFA) atau analisis faktor, yaitu dengan cara melihat table component matrix.

Jika dalam tabel component matrix terdapat dua kolom atau lebih maka terdapat pernyataan yang tidak valid dari kuesioner. Sehingga peneliti diwajibkan untuk mengeluarkan indikator yang memiliki Measures of Sampling Adequacy (MSA) dibawah 0.50 , jika nilai yang dibawah 0.50 sudah habis, maka yang dikeluarkan adalah yang memiliki MSA terkecil.

Dengan cara ini pada akhirnya akan menghasilkan pernyataan yang valid apabila dalam table component matrix hanya terbentuk satu komponen saja (Adhilla, 2015). Kriteria signifikansi terhadap item-item pertanyaan dalam penelitian ini didasarkan pada signifikansi praktis (practical significance) (Hair et al., 1998) seperti terlihat pada tabel berikut: Signifikansi Faktor Loading

\begin{tabular}{|l|l|}
\hline \multicolumn{1}{|c|}{ Faktor Loading } & \multicolumn{1}{c|}{ Keterangan } \\
\hline Lebih besar dari 0.30 & Level minimal \\
\hline Lebih besar dari 0.40 & Sangat Penting \\
\hline Lebih besar dari 0.50 & Signifikan \\
\hline
\end{tabular}

\section{Uji Reliabilitas}

Suatu data dikatakan reliabel apabila dua atau lebih peneliti dalam objek yang sama menghasilkan data yang sama (Sugiyono, 2016). Suatu data dikatakan reliabel jika cronbatch's alpha $>0,6$

\section{Teknik Analisis Data}

1. Analisis Regresi Berganda

$$
Y=a+b_{1} x_{1}+b_{2} x_{2}+b_{3} x_{3}
$$

Keterangan :

Y : variabel Kinerja Karyawan

a : Konstanta

b1,b2,b3,b4 : Koefisien regresi

X1 : Variabel Disversity

$\mathrm{X} 2$ : Varibel employee Support

X3 : Variabel Environment

\section{Uji Hipotesis}

1. Uji Parsial (Uji T)

Uji signifikan parsial (uji-t) menunjukan seberapa besar pengaruh variabel bebas secara individu terhadap variabel terikat. Kriteria pengambilan keputusan:

H0 diterima jika t-hitung < t-tabel pada a $5 \%$

H0 ditolak jika t-hitung > t-tabel pada $\alpha$ $5 \%$

\section{Uji Simultan (Uji F)}

Uji signifikan simultan (Uji F) pada dasarnya menunjukan apakah semua variabel bebas (X) yang dimasukkan dalam model mempunyai pengaruh secara bersama-sama terhadap variabel terikat (Y). Kriteria pengambilan keputusan :

$\mathrm{H} 0$ diterima jika $\mathrm{F}$ hitung $<\mathrm{F}$ tabel pada $\alpha=5 \%$

$\mathrm{H} 0$ ditolak jika $\mathrm{F}$ hitung $>\mathrm{F}$ tabel pada $\alpha=5 \%$

\section{Uji Koefisien Determinasi}

Koefesien determinasi $\left(\mathrm{R}_{2}\right)$ digunakan untuk mengukur seberapa besar kemampuan model dalam menerangkan variabel terikat. Jika $\mathbf{R}_{2}$ semakin besar (mendekati satu), maka dikatakan bahwa pengaruh variabel bebas (X1, X2 dan X3) adalah besar terhadap variabel terikat $(Y)$. hal ini berarti model yang dipergunakan semakin kuat menerangkan pengaruh varibel bebas yang diteliti terhadap variabel terikat.

Sebaliknya, jika $\mathrm{R}_{2}$ semakin kecil (mendekati nol), maka dapat dikatakan bahwa pengaruh varibel bebas (X1, X2 dan X3), adalah kecil terhadap variabel terikat. Hal ini berarti model yang digunakan tidak kuat untuk menerangkan pengaruh varibel bebas yang diteliti terhadap variabel terikat. 


\section{HASIL PENELITIAN DAN PEMBAHASAN}

\section{Hasil Analisis Responden}

Data yang digunakan merupakan hasil jawaban dari para responden yang bekerja sebagai karyawan di PT. Aqua Golden Misisipi Citeureup. Hasil dari data responden adalah informasi untuk mengetahui apakah Corporate Social Responsibilty (CSR) Perusahaan (diversity, employee support \& environment) berpengaruh Terhadap Kinerja Karyawan. Jumlah kuesioner yang disebar sebanyak 90 kuesioner dengan responden karyawan PT. Aqua Golden Misisipi Citeureup yang sedang mengikuti program pelatihan CSR, dengan data responden sebagai berikut:

Karakteristik Responden Berdasarkan Jenis Kelamin

\begin{tabular}{|l|l|l|}
\hline \multirow{2}{*}{ Jenis Kelamin } & \multicolumn{2}{|c|}{ Kuesioner } \\
\cline { 2 - 3 } & Disebar & Kembali \\
\hline Laki - laki & 69 & 69 \\
\hline Perempuan & 21 & 21 \\
\hline Total & 90 & 90 \\
\hline
\end{tabular}

Karakteristik Responden Berdasarkan Pekerjaan

\begin{tabular}{|c|c|c|}
\hline \multirow[t]{2}{*}{ Divisi } & \multicolumn{2}{|c|}{ Kuesioner } \\
\hline & Disebar & Kembali \\
\hline PRODUKSI 1 & 23 & 23 \\
\hline S HE & 4 & 4 \\
\hline PRODUKSI 3 & 23 & 23 \\
\hline PRODUKSI 2 & 23 & 23 \\
\hline TEKNIK & 9 & 9 \\
\hline LOGISTIK & 8 & 8 \\
\hline Total & 90 & 90 \\
\hline
\end{tabular}

\section{Hasil Penelitian}

1. Hasil Uji Validitas

a. Diversity (Perbedaan)

Pengujian instrumen untuk variabel Diversity (X1) dilakukan sebanyak 1 (satu) tahap yaitu dengan menghilangkan variabelvariabel yang memiliki nilai $M S A$ di bawah 0,500 dan variabel-variabel yang paling kecil yang dianggap tidak valid sampai terbentuk satu componen matriks yang mampu membentuk satu faktor Diversity (X1). Banyaknya item pertanyaan dalam variabel ini berjumlah 7 (tujuh) item pertanyaan yang kemudian direduksi menjadi beberapa item pertanyaan yang mampu menjelaskan atau mewakili variabel Diversity (X1). Dalam tahap ini item pertanyaan X1.6 dihilangkan karena nilai MSA dibawah 0,500 atau nilai MSA lebih kecil dari item pertanyaan yang lain.

Hasil Uji Validitas pertama Diversity Nilai Component Matrix

\begin{tabular}{|l|r|r|}
\hline \multirow{2}{*}{} & \multicolumn{2}{|c|}{ Component } \\
\cline { 2 - 3 } & 1 & \multicolumn{1}{c|}{2} \\
\hline $\mathrm{x} 1.1$ & 0,704 & 0,263 \\
\hline $\mathrm{x} 1.2$ & 0,811 & $-0,090$ \\
\hline $\mathrm{x} 1.3$ & 0,782 & $-0,321$ \\
\hline $\mathrm{x} 1.4$ & 0,606 & $-0,463$ \\
\hline $\mathrm{x} 1.5$ & 0,661 & $-0,003$ \\
\hline $\mathrm{x} 1.6$ & 0,206 & 0,827 \\
\hline $\mathrm{x} 1.7$ & 0,774 & 0,326 \\
\hline
\end{tabular}

Hasil akhir dari pengujian instrument untuk variabel Diversity (X1) diperoleh nilai Kaiser-MeyerOlkin Measure of Sampling Adequacy sebesar 0,705 menandakan bahwa instrumen sudah valid karena memenuhi batas 0,500 (0,705 > 0,500). Kemudian item-item pertanyaan yang mewakili variabel Diversity (X1) dapat dilihat pada tabel berikut: 
Hasil Uji Validitas terakhir Diversity Nilai Component Matrix

\begin{tabular}{|l|l|}
\hline & Component \\
\cline { 2 - 2 } & 1 \\
\hline $\mathrm{X} 1.1$ & 0,696 \\
\hline $\mathrm{X} 1.2$ & 0,811 \\
\hline $\mathrm{X} 1.3$ & 0,793 \\
\hline $\mathrm{X} 1.4$ & 0,621 \\
\hline $\mathrm{X} 1.5$ & 0,666 \\
\hline $\mathrm{X} 1.7$ & 0,762 \\
\hline
\end{tabular}

b. Employee Support (Dukungan Karyawan)

Pengujian instrument untuk variabel Employee Support (X2) dilakukan sebanyak 20 (dua puluh) tahap yaitu dengan menghilangkan variabel-variabel yang memiliki nilai MSA di bawah 0,500 dan variabelvariabel yang paling kecil yang dianggak tidak valid sampai terbentuk satu instrumen matriks yang mampu membentuk satu innstrumen Employee Support (X2). Banyaknya item pertanyaan dalam variabel ini berjumlah 28 (dua puluh delapan) item pertanyaan yang kemudian direduksi menjadi beberapa item pertanyaan yang mampu menjelaskan atau mewakili variabel Employee Support (X2). Dalam tahap ini item pertanyaan $\mathrm{X} 2.2, \mathrm{X} 2.5, \mathrm{X} 2.6, \mathrm{X} 2.11, \mathrm{X} 2.12$, $\mathrm{X} 2.13, \mathrm{X} 2.15, \mathrm{X} 2.16, \mathrm{X} 2.17, \mathrm{X} 2.19$, $\mathrm{X} 2.20, \mathrm{X} 2.21, \mathrm{X} 2.22, \mathrm{X} 2.23, \mathrm{X} 2.24$, $\mathrm{X} 2.25, \quad \mathrm{X} 2.26, \quad \mathrm{X} 2.27, \quad \mathrm{X} 2.28$ dihilangkan karena nilai MSA dibawah 0,50 atau nilai $M S A$ lebih kecil dari item pertanyaan yang lain.
Hasil Uji Validitas pertama Employee Support Nilai Component Matrix

\begin{tabular}{|l|c|c|c|c|c|c|c|c|c|}
\hline & \multicolumn{7}{|c|}{ Component } \\
\cline { 2 - 10 } & 1 & 2 & 3 & 4 & 5 & 6 & 7 & 8 & 9 \\
\hline$\times 2.1$ & 0,703 & 0,344 & $-0,105$ & 0,088 & 0,006 & $-0,058$ & 0,209 & $-0,046$ & $-0,069$ \\
\hline$\times 2.2$ & 0,691 & 0,175 & 0,317 & $-0,424$ & $-0,124$ & $-0,263$ & 0,054 & $-0,055$ & $-0,138$ \\
\hline$\times 2.3$ & 0,799 & 0,251 & $-0,072$ & 0,235 & 0,026 & 0,160 & $-0,152$ & $-0,087$ & $-0,134$ \\
\hline$\times 2.4$ & 0,807 & $-0,011$ & $-0,006$ & $-0,111$ & $-0,055$ & $-0,121$ & 0,014 & $-0,293$ & 0,128 \\
\hline$\times 2.5$ & 0,698 & $-0,029$ & $-0,053$ & 0,012 & $-0,485$ & $-0,116$ & $-0,237$ & $-0,032$ & $-0,294$ \\
\hline$\times 2.6$ & 0,689 & $-0,099$ & $-0,089$ & $-0,009$ & $-0,373$ & $-0,126$ & 0,095 & $-0,254$ & $-0,362$ \\
\hline$\times 2.7$ & 0,750 & $-0,374$ & $-0,314$ & 0,178 & 0,032 & 0,011 & 0,129 & $-0,030$ & $-0,114$ \\
\hline$\times 2.8$ & 0,651 & $-0,152$ & $-0,192$ & 0,246 & 0,424 & $-0,024$ & $-0,041$ & 0,362 & 0,003 \\
\hline$\times 2.9$ & 0,587 & 0,138 & $-0,285$ & $-0,156$ & 0,357 & 0,231 & $-0,093$ & $-0,074$ & 0,191 \\
\hline$\times 2.10$ & 0,765 & $-0,089$ & 0,247 & 0,142 & 0,099 & 0,049 & $-0,057$ & $-0,055$ & $-0,034$ \\
\hline$\times 2.11$ & 0,240 & $-0,217$ & 0,597 & $-0,059$ & 0,359 & 0,038 & 0,024 & $-0,357$ & 0,193 \\
\hline$\times 2.12$ & 0,269 & 0,062 & 0,527 & 0,169 & 0,165 & $-0,116$ & $-0,620$ & 0,044 & 0,045 \\
\hline$\times 2.13$ & 0,299 & $-0,210$ & 0,369 & 0,178 & $-0,307$ & 0,523 & 0,004 & 0,193 & 0,118 \\
\hline$\times 2.14$ & 0,514 & 0,061 & $-0,120$ & $-0,464$ & $-0,206$ & 0,025 & 0,177 & 0,372 & 0,146 \\
\hline$\times 2.15$ & 0,390 & $-0,246$ & 0,441 & $-0,354$ & 0,218 & $-0,385$ & 0,181 & 0,096 & 0,128 \\
\hline$\times 2.16$ & 0,552 & $-0,265$ & $-0,297$ & $-0,153$ & $-0,298$ & $-0,113$ & $-0,130$ & 0,290 & 0,355 \\
\hline$\times 2.17$ & 0,638 & $-0,283$ & 0,153 & 0,119 & 0,235 & $-0,193$ & 0,045 & 0,042 & 0,062 \\
\hline$\times 2.18$ & 0,574 & $-0,138$ & $-0,041$ & 0,375 & $-0,080$ & 0,451 & $-0,228$ & 0,049 & 0,061 \\
\hline$\times 2.19$ & 0,055 & 0,607 & 0,189 & 0,268 & 0,297 & $-0,072$ & 0,339 & 0,149 & $-0,357$ \\
\hline$\times 2.20$ & 0,011 & 0,550 & $-0,322$ & 0,397 & 0,170 & $-0,349$ & $-0,223$ & 0,055 & 0,004 \\
\hline$\times 2.21$ & $-0,079$ & 0,178 & $-0,576$ & 0,402 & $-0,205$ & $-0,277$ & 0,072 & $-0,191$ & 0,295 \\
\hline$\times 2.22$ & 0,277 & $-0,239$ & $-0,507$ & $-0,152$ & 0,414 & 0,388 & 0,247 & 0,048 & $-0,036$ \\
\hline$\times 2.23$ & 0,250 & 0,703 & $-0,129$ & $-0,357$ & 0,225 & 0,182 & $-0,191$ & 0,119 & $-0,202$ \\
\hline$\times 2.24$ & 0,015 & 0,671 & 0,077 & $-0,078$ & $-0,093$ & 0,374 & $-0,209$ & $-0,306$ & 0,240 \\
\hline$\times 2.25$ & 0,346 & 0,556 & 0,065 & $-0,252$ & $-0,109$ & 0,212 & 0,429 & $-0,207$ & 0,233 \\
\hline$\times 2.26$ & 0,274 & 0,125 & 0,167 & 0,692 & $-0,009$ & $-0,235$ & 0,312 & $-0,069$ & 0,301 \\
\hline$\times 2.27$ & 0,163 & 0,658 & 0,197 & $-0,082$ & $-0,160$ & $-0,198$ & $-0,056$ & 0,408 & 0,229 \\
\hline$\times 2.28$ & $-0,084$ & 0,096 & 0,495 & 0,452 & $-0,241$ & 0,308 & 0,327 & 0,251 & $-0,103$ \\
\hline
\end{tabular}

Hasil akhir dari pengujian instrument untuk variabel Employee Support (X2) diperoleh nilai KaiserMeyer-Olkin Measure of Sampling Adequacy sebesar 0,873 menandakan bahwa instrument sudah valid karena memenuhi batas $0,50 \quad(0,873 \quad>$ 0,500). Kemudian item-item pertanyaan yang valid dapat dilihat pada tabel berikut:

Hasil Uji Validitas terakhir Employee Support Nilai Component Matrix

\begin{tabular}{|l|r|}
\hline \multirow{2}{*}{} & Component \\
\cline { 2 - 2 } & 1 \\
\hline $\mathrm{x} 2.1$ & 0,714 \\
\hline $\mathrm{x} 2.3$ & 0,832 \\
\hline $\mathrm{x} 2.4$ & 0,749 \\
\hline $\mathrm{x} 2.7$ & 0,801 \\
\hline $\mathrm{x} 2.8$ & 0,725 \\
\hline $\mathrm{x} 2.9$ & 0,668 \\
\hline $\mathrm{x} 2.10$ & 0,764 \\
\hline $\mathrm{x} 2.14$ & 0,443 \\
\hline $\mathrm{x} 2.18$ & 0,644 \\
\hline
\end{tabular}


c. Enviroment (Lingkungan)

Pengujian instrumen untuk variabel Environment

dilakukan sebanyak 12 (dua belas) tahap yaitu dengan menghilangkan variabel-variabel yang memiliki nilai MSA di bawah 0,500 dan variabelvariabel yang paling kecil yang dianggak tidak valid sampai terbentuk satu componen matriks yang mampu membentuk satu faktor Environment $\left(\mathrm{X}_{3}\right)$. Banyaknya item pertanyaan dalam variabel ini berjumlah 18 (delapan belas) item pertanyaan yang kemudian direduksi menjadi beberapa item pertanyaan yang mampu menjelaskan atau mewakili variabel Environment (X3). Dalam tahap ini item pertanyaan X3.2, X3.3, X3.5, X3.8, X3.11, X3.12, X3.13, X3.14, X3.15, X3.16, X3.17 dihilangkan karena nilai $M S A$ dibawah 0,50 atau nilai $M S A$ lebih kecil dari item pertanyaan yang lain.

Hasil Uji Validitas pertama Environment Nilai MSA

\begin{tabular}{|l|r|r|r|r|r|}
\hline & \multicolumn{5}{|c|}{ Component } \\
\cline { 2 - 6 } & 1 & \multicolumn{1}{c|}{2} & \multicolumn{1}{c|}{3} & \multicolumn{1}{c|}{4} & \multicolumn{1}{c|}{5} \\
\hline x3.1 & 0,660 & 0,153 & $-0,239$ & 0,141 & $-0,096$ \\
\hline x3.2 & 0,562 & 0,561 & $-0,336$ & 0,177 & $-0,150$ \\
\hline x3.3 & 0,786 & 0,036 & $-0,122$ & $-0,071$ & $-0,331$ \\
\hline x3.4 & 0,814 & 0,244 & $-0,166$ & 0,070 & $-0,201$ \\
\hline x3.5 & 0,703 & $-0,212$ & 0,075 & 0,443 & 0,000 \\
\hline x3.6 & 0,654 & $-0,026$ & 0,340 & 0,410 & $-0,111$ \\
\hline x3.7 & 0,730 & $-0,274$ & 0,163 & $-0,176$ & $-0,194$ \\
\hline x3.8 & 0,702 & $-0,304$ & 0,011 & $-0,407$ & 0,112 \\
\hline x3.9 & 0,549 & $-0,035$ & 0,072 & 0,018 & $-0,327$ \\
\hline x3.10 & 0,762 & 0,227 & 0,113 & $-0,155$ & $-0,093$ \\
\hline x3.11 & 0,344 & 0,461 & 0,531 & $-0,233$ & 0,299 \\
\hline x3.12 & 0,386 & 0,119 & 0,544 & 0,143 & 0,454 \\
\hline x3.13 & 0,457 & $-0,117$ & $-0,439$ & 0,401 & 0,432 \\
\hline x3.14 & 0,376 & 0,690 & $-0,169$ & $-0,172$ & 0,357 \\
\hline x3.15 & 0,526 & $-0,309$ & $-0,198$ & 0,248 & 0,419 \\
\hline x3.16 & 0,713 & $-0,010$ & $-0,097$ & $-0,501$ & 0,068 \\
\hline x3.17 & 0,386 & $-0,479$ & $-0,391$ & $-0,379$ & 0,255 \\
\hline x3.18 & 0,621 & $-0,442$ & 0,394 & 0,047 & $-0,028$ \\
\hline & Hasil & akhir & dari & pengujian \\
instrument & & untuk & variabel \\
\hline
\end{tabular}

Environment (X3) diperoleh nilai

Kaiser-Meyer-Olkin Measure of Sampling Adequacy sebesar 0,848 menandakan bahwa instrumen sudah valid karena memenuhi batas 0,50
$(0,848>0,500)$. Kemudian itemitem pertanyaan yang valid dapat dilihat pada tabel berikut:

Hasil Uji Validitas terakhir Environment Nilai MSA

\begin{tabular}{|l|c|}
\hline & Component \\
\cline { 2 - 2 } & 1 \\
\hline$\times 3.1$ & 0,656 \\
\hline$\times 3.4$ & 0,806 \\
\hline$\times 3.6$ & 0,717 \\
\hline$\times 3.7$ & 0,757 \\
\hline$\times 3.9$ & 0,655 \\
\hline$\times 3.10$ & 0,768 \\
\hline x3.18 & 0,682 \\
\hline
\end{tabular}

d. Kinerja Karyawan

Pengujian instrumen untuk variabel Kinerja (Y) dilakukan sebanyak 10 (sepuluh) tahap yaitu dengan menghilangkan variabelvariabel yang memiliki nilai $M S A$ di bawah 0,50 dan variabel-variabel yang paling kecil yang dianggak tidak valid sampai terbentuk satu componen matriks yang mampu membentuk satu faktor Kinerja (Y). Banyaknya item pertanyaan dalam variabel ini berjumlah 15 (lima belas) item pertanyaan yang kemudian direduksi menjadi beberapa item pertanyaan yang mampu menjelaskan atau mewakili variabel kinerja (Y). Dalam tahap ini item pertanyaan Y2, Y3, Y4. Y8, Y10, Y11, Y12, Y14, Y15 dihilangkan karena nilai MSA dibawah 0,50 atau nilai $M S A$ lebih kecil dari item pertanyaan yang lain. 
Hasil Uji Validitas pertama Kinerja Karyawan Nilai MSA

\begin{tabular}{|l|r|r|r|r|r|r|}
\hline & \multicolumn{7}{|c|}{ Component } \\
\cline { 2 - 7 } & \multicolumn{1}{|c|}{1} & \multicolumn{1}{c|}{2} & \multicolumn{1}{c|}{3} & \multicolumn{1}{c|}{4} & \multicolumn{1}{c|}{5} & \multicolumn{1}{c|}{6} \\
\hline y.1 & 0,542 & 0,074 & 0,529 & 0,084 & $-0,107$ & $-0,105$ \\
\hline y.2 & 0,301 & 0,457 & 0,613 & $-0,037$ & $-0,357$ & 0,077 \\
\hline y.3 & 0,178 & 0,671 & $-0,006$ & 0,563 & 0,191 & 0,179 \\
\hline y.4 & 0,127 & 0,635 & $-0,370$ & $-0,348$ & 0,356 & 0,156 \\
\hline y.5 & 0,820 & 0,326 & $-0,030$ & $-0,235$ & $-0,131$ & 0,170 \\
\hline y.6 & 0,566 & $-0,034$ & 0,107 & $-0,628$ & $-0,027$ & $-0,332$ \\
\hline y.7 & 0,650 & $-0,210$ & 0,173 & $-0,204$ & 0,533 & $-0,039$ \\
\hline y.8 & 0,037 & $-0,174$ & 0,539 & 0,088 & 0,551 & $-0,090$ \\
\hline y.9 & 0,626 & $-0,282$ & 0,273 & 0,163 & $-0,310$ & 0,343 \\
\hline y.10 & 0,076 & $-0,562$ & $-0,130$ & $-0,380$ & $-0,015$ & 0,622 \\
\hline y.11 & 0,468 & 0,060 & $-0,472$ & 0,088 & 0,102 & 0,083 \\
\hline y.12 & 0,495 & 0,058 & $-0,574$ & 0,076 & $-0,229$ & $-0,082$ \\
\hline y.13 & 0,800 & 0,001 & $-0,195$ & 0,062 & $-0,018$ & $-0,312$ \\
\hline y.14 & 0,571 & $-0,214$ & 0,002 & 0,414 & 0,243 & 0,302 \\
\hline y.15 & 0,379 & $-0,527$ & $-0,245$ & 0,393 & $-0,057$ & $-0,329$ \\
\hline
\end{tabular}

Hasil akhir dari pengujian instrument untuk variabel Kinerja (Y) diperoleh nilai Kaiser-MeyerOlkin Measure of Sampling Adequacy sebesar 0,828 menandakan bahwa instrumen sudah valid karena memenuhi batas $0,50 \quad(0,828>$ 0,500). Kemudian item-item pertanyaan yang valid dapat dilihat pada tabel berikut:

Hasil Uji Validitas terakhir Kinerja Karyawan Nilai MSA

\begin{tabular}{|l|r|}
\hline & Component \\
\cline { 2 - 2 } & \multicolumn{1}{|c|}{1} \\
\hline y.1 & 0,632 \\
\hline y.5 & 0,817 \\
\hline y.6 & 0,679 \\
\hline y.7 & 0,716 \\
\hline y.9 & 0,615 \\
\hline y.13 & 0,761 \\
\hline
\end{tabular}

2. Hasil Uji Reliabilitas

\begin{tabular}{|l|c|c|c|}
\hline \multicolumn{1}{|c|}{ Variabel } & $\begin{array}{c}\text { Cronbach } \\
\text { Alpha }\end{array}$ & $\begin{array}{c}\text { Koefisien } \\
\text { Alpha }\end{array}$ & Status \\
\hline Diversity $(\mathrm{X} 1)$ & 0,791 & 0,60 & Reliabel \\
\hline Employee Support $(\mathrm{X} 2)$ & 0,860 & 0,60 & Reliabel \\
\hline Environment $(\mathrm{X} 3)$ & 0,890 & 0,60 & Reliabel \\
\hline Kinerja (Y) & 0,732 & 0,60 & Reliabel \\
\hline
\end{tabular}

Dari tabel di atas menunjukan nilai Cronbach Alpha variabel Diversity (X1) sebesar 0,791, nilai Cronbach Alpha variabel Employee Support (X2) sebesar 0,860, nilai Cronbach Alpha variabel Environment (X3) sebesar 0,890 dan nilai Cronbach Alpha variabel Kinerja (Y) sebesar 0,732. Dari hasil tersebut terlihat koefisien Cronbach Alpha bernilai lebih besar dari 0,60 maka instrumen penelitian yang digunakan dalam penelitian dinyatakan reliabel.

3. Hasil Uji Regresi Linier Berganda Hasil Uji Regresi Linier Berganda

\begin{tabular}{|c|c|}
\hline Hasil model & $\begin{array}{c}\text { Unstandardized } \\
\text { Coefficients }\end{array}$ \\
\hline (Constant) & 2,171 \\
\hline Diversity & $-0,008$ \\
\hline Employee Support & 0,364 \\
\hline Environment & 0,142 \\
$\mathbf{Y = ~} \mathbf{2 , 1 7 1}-\mathbf{0 , 0 0 8 X _ { 1 }}+\mathbf{0 , 3 6 4 X _ { 2 }}+$ \\
$\mathbf{0 , 1 4 2 X}$
\end{tabular}

Keterangan :

a. Nilai konstanta persamaan di atas sebesar 2,171. Angka tersebut menunjukkan variabel kinerja karyawan bila variabel Coorporate Social Responsibility (Diversity, Employee Support, Environment) diabaikan.

b. Variabel Coorporate Social Responsibility (Diversity) memiliki nilai koefisien regresi sebesar $-0,008$. Nilai koefisien negatif menunjukkan hubungan negatif Coorporate Social Responsibility (Diversity) terhadap tingkat kinerja. Hal ini berarti bahwa jika terjadi kenaikan Coorporate Social Responsibility (Diversity), maka nilai kinerja karyawan akan mengalami peningkatan sebesar variabel penyalinya $-0,008$ dengan asumsi variabel independen yang lain dianggap konstan.

c. Variabel Coorporate Social Responsibility (Employee Support) memiliki nilai koefisien regresi sebesar 0,364 . Nilai koefisien positif menunjukkan hubungan positif Coorporate Social Responsibility (Employee Support) terhadap tingkat kinerja karyawan. Hal ini berarti bahwa jika terjadi kenaikan Coorporate Social Responsibility (Employee Support), maka nilai kinerja karyawan akan mengalami 
peningkatan sebesar variabel penyalinya 0,364 dengan asumsi variabel independen yang lain dianggap konstan.

d. Variabel Coorporate Social Responsibility (Enviromet) memiliki nilai koefisien regresi sebesar 0,142 . Nilai koefisien positif menunjukkan hubungan positif Coorporate Social Responsibility

(Environment) terhadap tingkat kinerja karyawan. Hal ini berarti bahwa jika terjadi kenaikan Coorporate Social Responsibility (Environment), maka nilai kinerja karyawan akan mengalami peningkatan sebesar variabel penyalinya 0,142 dengan asumsi variabel independen yang lain dianggap konstan.

4. Hasil Uji Parsial (Uji T)

Hasil uji t (Parsial)

\begin{tabular}{|l|r|c|}
\hline & t-hitung & \multicolumn{1}{l|}{ Sig } \\
\hline Constant & 3,084 & 0,003 \\
\hline Diversity & $-0,155$ & 0,877 \\
\hline $\begin{array}{l}\text { Employee } \\
\text { Support }\end{array}$ & 2,663 & 0,009 \\
\hline Environment & 1,438 & 0,154 \\
\hline
\end{tabular}

a. Diversity (X1)

Berdasarkan hasil statistik uji $\mathrm{t}$ untuk variabel diversity diketahui bahwa nilai $t_{\text {hitung }}$ sebesar $-0,155$ dengan nilai signifikansi 0,877 . Hal ini menunjukkan bahwa angka probabilitas signifikansi variabel Diversity (X1) lebih besar dari 0,05 yaitu $(0,877>0,05)$. Berdasarkan hasil tersebut dapat disimpulkan $\mathrm{H}_{0}$ diterima dan $\mathrm{H}_{\mathrm{a}}$ ditolak. Yang berarti tidak ada pengaruh signifikan diversity terhadap kinerja karyawan.

b. Employee Support (X2)

Berdasarkan hasil statistik uji t untuk variabel Employee Support diketahui bahwa nilai $t_{\text {hitung }}$ sebesar 2,663 dengan nilai signifikansi 0,009 . Hal ini menunjukkan bahwa angka probabilitas signifikansi variabel Employee Support (X2) lebih kecil dari 0,05 yaitu $(0,009<$ 0,05). Berdasarkan hasil tersebut dapat disimpulkan $\mathrm{H}_{\mathrm{a}}$ diterima dan $\mathrm{H}_{0}$ ditolak. Yang berarti ada pengaruh signifikan Employee Support terhadap kinerja karyawan.

c. Environment (X3)

Berdasarkan hasil statistik uji t untuk variabel Environment diketahui bahwa nilai $t_{\text {hitung }}$ sebesar 1,438 dengan nilai signifikansi 0,154 . Hal ini menunjukkan bahwa angka probabilitas signifikansi variabel Environment (X3) lebih kecil dari 0,05 yaitu $(0,154>0,05)$. Berdasarkan hasil tersebut dapat disimpulkan $\mathrm{H}_{0}$ diterima dan $\mathrm{H}_{\mathrm{a}}$ ditolak. Yang berarti tidak ada pengaruh signifikan Environment terhadap kinerja karyawan.

5. Hasil Uji Simultan (Uji F)

Hasil Uji F (Simultan)

\begin{tabular}{|c|c|}
\hline F hitung & Sig \\
\hline 4,001 & $0,010^{\mathrm{b}}$ \\
\hline
\end{tabular}

Berdasarkan hasil uji $\mathrm{F}$ diperoleh nilai $F_{\text {hitung }}$ sebesar 4,001 dengan nilai signifikansi 0,010 dimana nilai signifikansi lebih kecil dari 0,05 $(0,010<0,05)$. dengan demikian hipotesis yang menyatakan terdapat pengaruh positif dan signifikan antara Diversity, Employee Support, dan Environment secara bersama-sama terhadap kinerja karyawan terbukti.

6. Hasil Uji Koefisien Determinasi Hasil Uji Koefisien Determinasi $\left(\mathrm{R}^{2}\right)$

\begin{tabular}{|c|r|}
\hline Model & R Square \\
\hline 1 & 0,122 \\
\hline
\end{tabular}

Hasil R-square pada penelitian ini diperoleh nilai R-square sebesar 0,122 . Hal ini menunjukkan bahwa 
kinerja karyawan yang dipengaruhi Coorporate Social Responsibility (Diversity, Employee Support, Environment) sebesar $12,2 \%$ sedangkan sisanya $87,8 \%$ dipengaruhi faktor lain yang tidak diteliti dalam penelitian ini.

\section{Pembahasan}

1. Pengaruh diversity terhadap kinerja karyawan PT. Aqua Golden Misisipi Citeureup

Tidak ada pengaruh yang signifikan antara Diversity terhadap kinerja karyawan PT. Aqua Golden Misisipi Citeureup. Hal ini ditunjukan dari nilai $t_{\text {hitung }}-0,155$ dengan nilai signifikansi 0,877 dimana nilain signifikansi lebih besar dari 0,05 (0,877 $>0,05)$ dan koefisien regresi memiliki nilai negatif -0,008. Maka dalam penelitian ini tidak berhasil membuktikan hipotesis "ada pengaruh Diversity terhadap kinerja karyawan kontrak" tidak terbukti.

2. Pengaruh Employee Support terhadap kinerja karyawan PT. Aqua Golden Misisipi Citeureup

Ada pengaruh yang signifikan antara employee support terhadap kinerja karyawan PT. Aqua Golden Misisipi Citeureup. Hal ini ditunjukan dari nilai $t_{\text {hitumg }} 2,663$ dengan nilai signifikansi 0,009 dimana nilai signifikansi lebih kecil dari 0,05 (0,009 $<0,05)$ dengan koefisien regresi memiliki nilai positif 0,364. Maka dalam penelitian ini berhasil membuktikan bahwa hipotesis "ada pengaruh employee support terhadap kinerja karyawan kontrak" terbukti.

\section{Pengaruh Environment terhadap kinerja karyawan PT. Aqua Golden Misisipi Citeureup}

Tidak ada pengaruh yang signifikan antara Environment terhadap keputusan kinerja karyawan PT. Aqua Golden Misisipi Citeureup hal ini ditunjukan dari nilai $\mathrm{t}_{\text {hitung }} 1,438$ dengan nilai signifikansi 0,154 dimana nilai signifikansi lebih besar dari $0,05(0,154$ $>0,05)$ dengan koefisien regresi memiliki nilai positif 0,142 . Maka dalam penelitian ini tidak berhasil membuktikan hipotesis "ada pengaruh environment terhadap kinerja karyawan kontrak" tidak terbukti.

\section{KESIMPULAN DAN SARAN}

\section{Kesimpulan}

1. Variabel diversity (perbedaan) secara parsial tidak mempunyai pengaruh terhadap kinerja karyawan PT. Aqua Golden Misisipi Citeureup.

2. Variabel employee support (dukungan karyawan) secara parsial mempunyai pengaruh terhadap kinerja karyawan PT. Aqua Golden Misisipi Citeureup.

3. Variabel environment (lingkungan) tidak mempunyai pengaruh signifikan terhadap kinerja karyawan PT. Aqua Golden Misisipi Citeureup.

4. Secara simultan variabel diversity (X1), employee support (X2) dan environment (X3) secara bersama-sama mempengaruhi kinerja dan memiliki pengaruh signifikan terhadap kinerja karyawan PT. Aqua Golden Misisipi Citeureup.

\section{Saran}

1. Perusahaan perlu meningkatkan konsep Employee support (dukungan karyawan) terhadap karyawan diantaranya konsep insentif yang lebih baik, perusahaan perlu memberikan sanksi yang tegas kepada karyawan yang melanggar aturan-aturan K3. Hal ini dimaksudkan agar karyawan lebih disiplin dan juga untuk menghindari terjadinya kecelakaan atau kerusakan akibat kerja. Meningkatkan pelaksanaan Sistem Manajemen Keselamatan dan 
Kesehatan Kerja (SMK3) dengan baik, karena komitmen yang kuat dan perhatian yang besar dari manajemen perusahaan mengenai masalah $\mathrm{K} 3$ dapat memotivasi karyawan untuk memperhatikan keselamatan dan kesehatannya sewaktu bekerja dan meningkatkan fasilitas dan sarana kerja yang dapat menunjang karyawan dalam menyelesaikan pekerjaannya.

2. Perusahaan perlu juga meningkatkan konsep environment (lingkungan) yang telah ada di perusahaan meskipun variabel ini tidak berpengaruh signifikan terhadap kinerja, supaya karyawan merasa terfasilitasi dalam setiap pekerjaan. Hal ini di maksudkan agar karyawan dapat bekerja dengan suasana lingkungan yang lebih nyaman, sehingga dapat meningkat kinerja para karyawan.

3. Walaupun diversity (perbedaan) tidak memberikan pengaruh yang signifikan terhadap kinerja, bukan berarti faktor diversity (perbedaan) diabaikan. Pimpinan perlu memperhatikan lagi apakah konsep diversity sekarang sudah diterapkan dengan baik dan sesuai dengan yang diharapkan karyawan, sehingga perlu diperhatikan dan dipertimbangkan lagi sebelum mengambil keputusan.

4. Bertitik tolak dari hasil analisis dan pembahasan sebelumnya, maka sebagai hasil penelitian direkomendasikan bahwa variabel diversity, employee support dan environment bukanlah faktor utama dalam usaha meningkatkan kinerja karyawan. Masih terdapat faktor-faktor lain yang mepengaruhi kinerja karyawan. Oleh karena itu disarankan untuk melakukan penelitian lanjutan yang lebih mendalam misalnya dengan menambahkan variabel endogen (variabel bebas/faktor) seperti, kompensasi, komitmen karyawan, pendidikan dan pelatihan, work life balance dan faktor lainnya sehingga hasilnya lebih representatif dan lengkap. Selain itu konsep diversity dapat memicu efek yang berbeda pada perusahaan yang masih berukuran kecil, oleh karena itu penelitian lebih lanjut perlu diversifikasi sampel dengan menggunakan perusahaan asing atau multinasional.

\section{DAFTAR PUSTAKA}

Adhila, Fitroh, Dyah Fitriani, dan Denny Ismanto. (2013). Modul Praktikum Statistik 2. Yogyakarta: Universitas Ahmad Dahlan.

Anatan, Lia. (2009). Corporate Social Responsibility (CSR): Tinjauan Teoritis dan Praktik di Indonesia. Jurnal Manajemen Vol.8 No.2: Maranantha Chistian University.

Azheri, Busyra. (2011). Corporate Social Responsibility dari Voluntary Menjadi Mandatory. Jakarta: PT. Raja Grafindo Persada.

Heryani, Titin dan Zunaidah. (2013). Analisis Pengaruh Penerapan Corporate Social Responsibility (Diversity \& Employee Support) Terhadap Kinerja Karyawan (Sudi Kasus PT. BATU RONA ADIMULYA). Jurnal Manajemen \& Bisnis Sriwijaya (Juni), Vol. 11, No. 2, Hal. 149-180.

Reynard, Peter \& Maya Forstater. (2002). Corporate Social Responsibility: Implications for small and medium Enterprises in Developing Countries. United Nations Industrial Development Organization (Unindo), Vienna.

Sugiyono. (2016). Metode Penelitian Bisnis. Bandung: ALFABETA. 